$$
\begin{array}{r}
\text { Pontifícia Universidade Católica } \\
\text { do Rio de Janeiro }
\end{array}
$$

Renata da Graça Aranha Boiteux

\title{
Itinerários político-afetivos na cultura portuguesa: uma leitura analítica das crônicas de António Lobo \\ Antunes
}

\section{Dissertação de Mestrado}

\begin{abstract}
Dissertação de Mestrado apresentada como requisito parcial para obtenção do grau de Mestre em Letras do Departamento de Letras da PUC-Rio como parte dos requisitos parciais para obtenção do título de Mestre em Letras.
\end{abstract}

Orientador: Prof. Alexandre Montaury Baptista Coutinho 


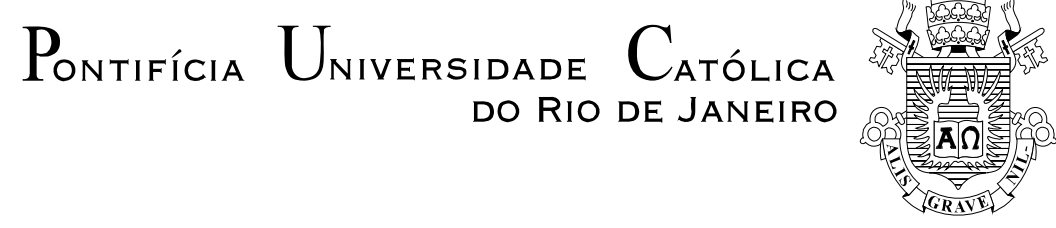

Renata da Graça Aranha Boiteux

\title{
Itinerários político-afetivos na cultura portuguesa: uma leitura analítica das crônicas de António Lobo Antunes
}

\begin{abstract}
Dissertação apresentada como requisito parcial para obtenção do grau de Mestre pelo programa de Pós-Graduação em Letras do Departamento de Letras do Centro de Teologia e Ciências Humanas da PUC-Rio. Aprovada pela Comissão Examinadora abaixo assinada.
\end{abstract}

Prof. Alexandre Montaury Baptista Coutinho
Orientador
Departamento de Letras - PUC-Rio

Profa. Angela Maria Thereza Lopes

UNESA

Prof. Eduardo Prazeres do Santos

UERJ

Profa. Denise Berruezo Portinari Coordenadora Setorial do Centro de Teologia e Ciências Humanas - PUC-Rio

Rio de Janeiro, 10 de setembro de 2010. 
Todos os direitos reservados. É proibida a reprodução total ou parcial do trabalho sem a autorização da universidade, da autora e do orientador.

\section{Renata da Graça Aranha Boiteux}

Graduou-se em Letras (Português - Francês) pela Universidade Federal do Rio de Janeiro, UFRJ. Durante a graduação participou de diversos cursos de extensão, seminários e congressos. Atualmente dedica-se a atividade de pesquisa e ao magistério.

\section{Ficha Catalográfica}

Boiteux, Renata da Graça Aranha

Itinerários político-afetivos na cultura portuguesa : uma leitura analítica das crônicas de António Lobo Antunes / Renata da Graça Aranha Boiteux ; orientador: Alexandre Montaury Baptista Coutinho. - 2010.

144 f. ; il. (col.) ; $30 \mathrm{~cm}$

Dissertação (mestrado) - Pontifícia Universidade Católica do Rio de Janeiro, Departamento de Letras, 2010.

Inclui bibliografia

1. Letras - Teses. 2. Literatura e cultura portuguesas. 3. Crônicas. 4. Antunes, António Lobo. 5. Salazarismo. 6. Guerras coloniais. I. Coutinho, Alexandre Montaury Baptista. II. Pontifícia Universidade Católica do Rio de Janeiro. Departamento de Letras. III. Título.

CDD: 800 
Aos meus filhos Sofia e Nicolau, ao meu marido Vitor Hugo e à minha mãe Heloisa. 


\section{Agradecimentos}

Ao CNPq pela bolsa, auxílio fundamental para a realização desta dissertação.

À PUC-Rio pela bolsa, pelo empréstimo de livros da Biblioteca, pela excelente estrutura da Universidade e por outros serviços essenciais às atividades de pesquisa.

Ao meu orientador, professor Alexandre Montaury, pelo acompanhamento vigilante durante todo o processo. Pela dedicação e pela paciência.

À professora Izabel Margato pelas suas aulas tão importantes para o meu conhecimento de Literatura e Cultura Portuguesa.

À professora Cleonice Berardinelli por me passar, além de conhecimento, a paixão pela Literatura Portuguesa.

À Chiquinha pelo carinho e amizade.

À Daniele e a todas as funcionárias do Departamento de Letras pela competência e carinho.

A todos os funcionários da PUC-Rio.

Ao meu marido pela compreensão e apoio nas horas mais difíceis.

Aos meus filhos por me fazerem crer que todo esforço vale a pena.

À minha mãe pela torcida.

Ao meu irmão, Rodrigo Graça Aranha, pela ajuda e preocupação.

E à minha sogra Sonia, pelo apoio de sempre com as crianças. Sem ela meus estudos seriam muito prejudicados, se possíveis. 


\section{Resumo}

Boiteux, Renata da Graça Aranha; Coutinho, Alexandre Montaury Baptista (Orientador). Itinerários político-afetivos na cultura portuguesa: uma leitura analítica das crônicas de António Lobo Antunes. Rio de Janeiro, 2010. 144p. Dissertação de Mestrado - Departamento de Letras, Pontifícia Universidade Católica do Rio de Janeiro.

Esta dissertação se organiza em torno da leitura e da análise de um conjunto de crônicas de António Lobo Antunes, publicadas em jornais e revistas e, posteriormente, reunidas em livro. Tratadas pelo autor como textos periféricos no escopo de sua obra, as crônicas assumem, nesta dissertação, lugar central pela sua especificidade de gênero e por revelarem, de forma condensada, temas que são fundamentais no projeto de escrita do autor. Consideradas por parte da crítica como "antecâmaras dos romances", as crônicas de Lobo Antunes privilegiam tanto o contexto das guerras coloniais portuguesas quanto às novas condições políticas no final do século XX em Portugal. Partindo de uma investigação acerca de práticas simbólicas e afetivas marcadas por estas novas condições políticas, culturais e sociais, esta dissertação busca formular argumentos que possibilitem uma leitura dessas narrativas breves como eficazes operadores de sentido para uma reflexão crítica de alguns impasses e desafios da cultura portuguesa contemporânea presentes na obra de António Lobo Antunes.

\section{Palavras-chave}

Literatura e Cultura Portuguesas; Crônicas, António Lobo Antunes; Salazarismo, Guerras Coloniais. 


\section{Resumé}

Boiteux, Renata da Graça Aranha; Coutinho, Alexandre Montaury Baptista (Orientateur). Itinéraires politico-affectifs dans la culture portugaise: une lecture analytique des Chroniques d'Antonio Lobo Antunes. Rio de Janeiro, 2010. 144p. Dissertation - Departamento de Letras, Pontifícia Universidade Católica do Rio de Janeiro.

Cette dissertation s'organise autours de la lecture et de l'analyse d'un ensemble de chroniques d'Antonio Lobo Antunes, publiées dans des journaux et revues et, postérieurement, réunies dans un livre. Traitées par l'auteur comme des textes périphériques dans l'objectif de son œuvre, les chroniques assument, dans cette dissertation, la place principale par sa particularité de genre et pour révéler de manière condensée, des thèmes qui sont fondamentaux pour le projet d'écriture de l'auteur. Considérées de la part de la critique comme "l'antichambre des romans”, les chroniques de Lobo Antunes privilégient autant le contexte des guerres coloniales portugaises que les nouvelles conditions politiques de la fin du XX au Portugal. En partant d'une recherche à propos des pratiques symboliques et affectives marquées par ces nouvelles conditions politiques, culturelles et sociales, cette dissertation cherche à formuler des arguments qui rendent possible une lecture de ces brèves narrations comme d'efficaces opérateurs de sens pour une réflexion critique des impasses et des défis de la culture portugaise contemporaine présents dans l’oeuvre de António Lobo Antunes..

\section{Mots-Clé}

Littérature et Culture Portugaise; Chroniques, António Lobo Antunes; Salazarisme, Guerres Coloniales. 


\section{Sumário}

$\begin{array}{lr}\text { Introdução } & 9\end{array}$

1. "Esta maneira de chorar dentro de uma palavra” 16

1.1. O testemunho da Guerra de Angola. $\quad 16$

1.2. A experiência Benjaminiana e a escrita Antuniana. 27

2. Itinerários polítifco-afetivos $\quad 39$

2.1. A representação da afetividade na cultura portuguesa 39

2.2. Para além de Portugal: Sentimentos universais. 54

3. Conclusão 73

$\begin{array}{ll}\text { Referências bibliográficas } & 78\end{array}$

$\begin{array}{ll}\text { Anexos } & 83\end{array}$ 